\title{
Article
}

\section{Teaching Psychomotor Skills in a Virtual Environment: An Educational Case Study}

\author{
Laura Plummer *(D), Lesley Smith, Elizabeth Cornforth $\mathbb{( 1 )}$ and Shweta Gore \\ MGH Institute of Health Professions, Boston, MA 02129, USA; lsmith1@mghihp.edu (L.S.); \\ ecornforth@mghihp.edu (E.C.); sgore@mghihp.edu (S.G.) \\ * Correspondence: lplummer@mghihp.edu
}

Citation: Plummer, L.; Smith, L.; Cornforth, E.; Gore, S. Teaching

Psychomotor Skills in a Virtual

Environment: An Educational Case Study. Educ. Sci. 2021, 11, 537. https://doi.org/10.3390/ educsci11090537

Academic Editor:

Carianne Bernadowski

Received: 13 August 2021

Accepted: 3 September 2021

Published: 14 September 2021

Publisher's Note: MDPI stays neutral with regard to jurisdictional claims in published maps and institutional affiliations.

\begin{abstract}
In March 2020, most physical therapy schools across the globe transitioned to online learning in response to the COVID-19 pandemic. This change posed unique challenges not only because it required adapting to new technology in a short period but, more importantly, it involved developing ways to teach hands-on psychomotor and clinical skills virtually while maintaining the quality of instruction. In response to the rapid transition, the physical therapy program at MGH Institute of Health Professions (IHP)designed and implemented a novel and effective coaching model to address the challenges. The model was developed based on experiential learning theory, constructivism, a coaching framework, and andragogical principles of feedback and reflection. Not only did the model meet its objectives of effectively teaching basic psychomotor skills in the virtual environment, but it may also have andragogical benefits that can be applied to traditional face-to-face methods. This case study describes the theoretical underpinning of the model, its development and implementation, the perceived effectiveness for learning psychomotor skills in a virtual environment, and the potential for broader relevance to future models of physical therapy education.
\end{abstract}

Keywords: health profession education; coaching; psychomotor skills; virtual learning

\section{Introduction}

In Spring 2020, higher education institutions globally were forced to close their doors and quickly pivot to virtual instruction. COVID-19 presented unprecedented challenges to higher education, particularly health professions education, because it required developing new ways to teach hands-on psychomotor and foundational pre-clinical skills virtually. During the pandemic, Physical Therapy (PT) educators were compelled to either delay instruction and assessment of psychomotor skills or develop virtual methods. Since PT has been regarded as a hands-on profession requiring traditional onsite instruction for effective learning of psychomotor skills, faculty were initially skeptical that meaningful teaching and learning could be accomplished in the online environment. However, the global pandemic demanded exploration of new perspectives and methods of instruction.

The decision to transition to remote teaching was particularly challenging for flipped classroom programs such as the Doctor of Physical Therapy (DPT) program at the IHP. Curricular philosophy at the IHP is based on constructivism. Constructivism focuses on both the individual and the environment for learning and emphasizes how students learn, recognizing that learners bring previous knowledge and experiences to the learning environment. New information is reconstructed in the context of prior experiences and knowledge to create new meaning. Engaging in reflection and metacognition are keys to constructivism [1-4]. Using this constructivist lens, the curriculum at the IHP encourages peer and team interaction to co-construct meaning from didactic material and lab experiences. Students use active learning, problem-solving, and collaboration to draw on past experiences and reflect on new learning to create meaning [5,6]. Before the pandemic, PT students at the IHP worked in small groups to apply pre-class asynchronous learning in both onsite laboratory and class case-based discussions. With the transition to remote 
learning, the faculty at the IHP needed to find a way to continue to effectively teach and assess psychomotor skills virtually while also maintaining the integrity of the andragogical foundation on which the curriculum was based. The innovative coaching model of virtual instruction and assessment of psychomotor skills was designed in response to these urgent needs following an extensive search of the literature on relevant educational theoretical frameworks and andragogical theory. The purpose of this case study was to describe the development, application, and initial outcomes of the innovative coaching model in the Doctor of Physical Therapy DPT program at the IHP and to describe its utility as a teaching modality in the future, considering the evolving physical education landscape.

\subsection{Andragogical Theory Applied to a Coaching Model}

The authors considered basic science, experiential learning theory, a coaching model framework, and literature on feedback and reflection throughout the development of the coaching model.

\subsubsection{Basic Science}

The ability to successfully teach psychomotor skills in a virtual environment is supported by basic science. Mirror neurons are a class of neuron that become active both when an individual executes a specific action, as well as when they observe another person performing the same or similar action $[7,8]$. Because of their activation during both observation and actively performing a task, they are thought to play a role in learning. This science can be applied to a virtual environment where students watch videos of a new skill, which may excite the needed neural connections, and then become an active participant performing the skill [8].

\subsubsection{Experiential Learning Theory (ELT)}

The innovative coaching model developed at the IHP incorporates concepts from ELT throughout the process. Like constructivism, ELT leverages learner-centered opportunities based on the principles that individuals learn best through experience [9]. ELT focuses on the process of learning and not just behavioral outcomes. Development in multiple domains - affective, perceptual, cognitive, and behavioral—is derived both from learner experiences and reflection [9]. The Educator Role Profile (ERP) was developed to assist educators in applying ELT concepts by matching teaching methods to the learning cycle $[10,11]$. The focus of the ERP is the role educators play interacting with, rather than on, students and includes four key styles and associated strategies: facilitator, subject matter expert, evaluator, and coach [12]. Educators adopt roles to help learners move around the learning cycle. ELT suggests that learners should be exposed to styles of teaching that match their preferences and be challenged to use a less preferred styles [11]. The coaching model used learner experiences, reflection, and different teaching roles described under ERP to help learners apply knowledge gained from various sources for broader growth in learning. Table 1 illustrates how different educator roles were incorporated in the innovative coaching model [11]. 
Table 1. The coaching model matched with Kolb educator role profile teaching styles.

\begin{tabular}{cll}
\hline Teaching Style & \multicolumn{1}{c}{ Style Definition (Kolb) } & \multicolumn{1}{c}{ Coaching Model Activities at IHP } \\
\hline Subject Expert & $\begin{array}{l}\text { Reflective authoritarian, analyzes and } \\
\text { organizes the subject; delivers knowledge by } \\
\text { lecture and text. }\end{array}$ & $\begin{array}{l}\text { Materials that blend theory and skill development } \\
\text { posted prior to the 1:1 session. }\end{array}$ \\
\hline $\begin{array}{c}\text { Standard Setter and } \\
\text { Evaluator }\end{array}$ & $\begin{array}{l}\text { Sets performance objectives, structures } \\
\text { performance activities to evaluate learning. }\end{array}$ & $\begin{array}{l}\text { Explicit instructions for process linking objectives to } \\
\text { assessment and rubrics for skill video, reflection, and } \\
\text { peer feedback. }\end{array}$ \\
\hline Coach & $\begin{array}{l}\text { Applied collaborative style, 1:1 with learners } \\
\text { to apply learning to context, feedback } \\
\text { mechanisms and development plans. }\end{array}$ & $\begin{array}{l}1: 1 \text { coaching sessions with student as the physical } \\
\text { therapist and family/roommate as a patient to create } \\
\text { authenticity for identified skills focus on feedback } \\
\text { with plan for refinement before the final video. }\end{array}$ \\
\hline Facilitator & $\begin{array}{l}\text { Warm affirming style; draw out motivation } \\
\text { and self-knowledge, creates personal } \\
\text { dialogue and relationships. }\end{array}$ & $\begin{array}{l}\text { Interaction in class to create a safe environment for } \\
\text { mistakes. Inclusion of family and roommates to } \\
\text { coaching sessions. Faculty and peer feedback } \\
\text { focused on positive aspects of performance. }\end{array}$ \\
\hline
\end{tabular}

\subsubsection{Coaching Model Framework}

The coaching model framework has gained prominence in medical education as a method for performance improvement, especially in competency-based medical education. Models from music and sports have been adapted to medical education and include direct observations of a learner's performance followed by individual feedback on strengths while also identifying performance gaps and developing strategies for improvement $[13,14]$. Academic coaching revolves around the needs and goals of the learners. An academic coach has been defined as "a person assigned to facilitate learners achieving their fullest potential. Coaches work with learners by evaluating performance via review of objective assessments, assisting the learner to identify needs and create a plan to achieve these, and helping the learner to be accountable" [15]. Whereas the coaching in medical education is focused on overall career development, the coaching model designed at the IHP applied the principles of coaching to specific curricular objectives for improving psychomotor skills in a virtual environment during the first semester of DPT education.

\subsubsection{Feedback}

Part of coaching involves giving feedback on areas of strength and areas that require improvement. The main purpose of feedback is to reduce the discrepancies between current performance and a goal $[15,16]$. Faculty at the IHP incorporated research on feedback to understand the complexities of the various types and levels of feedback, and how to effectively apply them to the different learning objectives of the coaching model.

\subsubsection{Reflection}

In addition to feedback, Jenson identifies reflection as a critical element of expert practice in PT and the means for continued learning and development [17]. In PT, reflection has been used to improve patient care, support clinical supervision, improve collaboration, and advance clinical reasoning [18]. Both feedback and reflection are critical to developing clinical reasoning skills and lifelong learning $[19,20]$.

A reflective practitioner is described as someone who uses reflection to learn from experiences to advance expertise [21]. Two integral forms of reflective practice include (1) reflection-in-action, which involves constant framing and reframing of the situation on the way to solutions that go beyond the limits of technical rationality, and (2) reflection-onaction, involving the revisiting, the reconsidering, and, in some cases, the reenacting of a previous action as elements of learning from and through experience. Both these reflective practices built throughout the curriculum help in nurturing novices as they move toward and into professional practice [21]. 
Different methods of implementation of reflection include written forms, multimedia approach, and videotaping. Written forms of reflection are the most reported form in the field of PT [18] and have been shown to improve clinical reasoning [18,22] enhance individual learning, and aid in practicing empathy $[18,23]$. Videotape analysis is another powerful learning tool for reflection or stimulating reflection [24]. Lähteenmäaki [25] determined that videotape extracts, when used in self-assessment and reflective discussions, helped PT students' progress when they were given more responsibility for their learning. The coaching model at the IHP incorporated reflection-in-action and reflection-on-action via elements of the written review process and video analysis.

\section{Materials and Methods}

The coaching model was developed as part of a quality improvement (QI) initiative to maintain the quality of learning in an online format during the pandemic. The case study describes the design and development of the coaching model, its implementation, and impact on learning outcomes.

\subsection{Development of the Coaching Model}

A cohort of 72 students enrolled at the IHP matriculated into the institution's PT program in June 2020. Students were in a variety of living situations, including some living with family, others with roommates, and several students living alone. Ages ranged from 21 to 42 years, with an average age of $24+3.9$ years. PT 601 Patient/Client Management was the first course in the IHP's DPT curriculum. The course introduces the Patient/Client Management model, International Classification of Functioning (ICF) [26], and psychomotor skills objectives focusing on systems review, tests and measures, and basic mobility skills using a case-based model.

\subsubsection{Preliminary Planning}

Following principles of coaching framework and ELT, 1:1 sessions were designed to allow time for feedback, reflection, and planning on performance improvement. Faculty met with the IHP's instructional designers to further enhance and refine the model. Instructional designers introduced course faculty to a resource which emphasized the importance of feedback using teaching a physical skill such as martial arts in the virtual environment [27]. The presentation described a model that promoted teaching asynchronously and coaching synchronously and encouraged 1:1 virtual time with the instructor to provide feedback [27]. Table 1 describes the components of the coaching model that were matched with the teaching styles of the educator role profiles laid out in ELT. Faculty reviewed course objectives and made preliminary decisions through experience and consensus on which psychomotor skills may be best taught and assessed in the virtual environment using the coaching model. Skills selected to be taught via the coaching model included vital signs (specifically blood pressure, heart rate, and respiratory rate), bed mobility (including supine to sit transfers), squat and stand pivot transfers, and palpation of anatomical structures around the knee.

\subsubsection{Preparatory Materials}

Faculty designed various preparatory materials including videos created by faculty and supplemental videos from PhysioU [28] of the psychomotor skills to be assessed, in addition to textbook readings, power-point slides, and notes on principles of transfers, positioning, safety, and body mechanics. The coaching model's assignment and rubrics were designed and included in the preparatory materials on the online learning management system, Brightspace Desire 2 LearnTM (D2L), one week before the virtual coaching sessions. Students had one week for independent practice of skills before the actual coaching session. 


\subsubsection{Coaching Session}

Students participated in a 1:1 twenty-minute coaching session with a faculty member or laboratory instructor (LI). Students recruited a family member/roommate and either performed the skills live during the coaching session or shared a pre-recorded video of themselves performing the skill with a participant. Students received 1:1 feedback and coaching from the instructor and were given the opportunity to ask questions and discuss a trajectory to improve the psychomotor skills.

LIs were local clinicians who regularly instructed in laboratory classes before the pandemic and were familiar with the skills taught in this course. For the 1:1 coaching session, $14 \mathrm{LI} /$ faculty were scheduled to meet individually with six students via the Zoom videoconferencing platform, each for a 20-minute session to cover a specific skill. Course faculty met with the LIs virtually prior to the coaching session to answer questions and ensure consistency across all sessions. LIs were given instructions and rubrics via D2L before the learning activity. After all students completed their first 1:1 coaching session on the first set of skills, they met with another LI to practice the second skill in the same format. Time spent in the 1:1 virtual lab for the students was $40 \mathrm{~min}$ total. One faculty member was available to trouble-shoot technology problems or answer questions during the session times.

\subsubsection{Discussion Board and Reflection}

After incorporating feedback from the coaching session, students were required to post a video of themselves performing the skill to a discussion board by the next day and were instructed to view and post feedback to at least one other student's video. They were also assigned to post a written reflection on how they would use the peer feedback they received on their own video to improve their performance. Students were graded on the quality and content of their peer feedback and self-reflection discussion board posts using a rubric and also received written feedback from instructors.

\subsubsection{Graded Assessment}

Peer feedback, self-reflection, and further opportunities for independent practice culminated in a graded final video assignment three days after the initial coaching session, thereby completing the learning cycle [11]. Unlike the discussion board video, where feedback and reflection could be seen by others in the class, students posted their final graded video as an independent assignment for individual grading and feedback. Expectations and grading instructions were created based on the transparency in teaching and learning philosophy where students were provided an explanation for the meaningfulness of the assignment and how it would help the student in future [29,30]. Faculty provided clear expectations and criteria for success via use of a rubric. The same LI/faculty graded the final video assessment for their 12 assigned students.

Faculty in two subsequent courses continued the coaching model with modifications such as the use of 2:1 coaching format. The 2:1 model allows for in-the-moment peer feedback between two students with cumulative feedback from one instructor and viewing pre-recorded videos during the coaching sessions rather than live demonstrations. Skills assessed in these courses included range of motion and muscle performance assessment of the shoulder, hip, knee, and ankle.

\section{Results}

Faculty developed a survey comprising of both open- and close-ended questions to measure student perceived effectiveness of, and satisfaction with, the coaching model (Appendix A). The survey was administered anonymously through D2L $\mathrm{L}^{\mathrm{TM}}$ after the completion of the three courses that used variations of the coaching model. Forty percent $(29 / 72)$ of the first year DPT students completed the survey. Please see Table 2 for results of the survey. 
Table 2. Coaching model survey results.

\begin{tabular}{|c|c|c|c|}
\hline Question & $\begin{array}{c}\text { Strongly } \\
\text { Agree/Agree } \\
\text { N (\%) }\end{array}$ & $\begin{array}{l}\text { Neutral } \\
\text { N (\%) }\end{array}$ & $\begin{array}{c}\text { Strongly } \\
\text { Disagree/Disagree } \\
\text { N (\%) }\end{array}$ \\
\hline $\begin{array}{l}\text { The pre-class materials helped to prepare for the 1:1 or small group } \\
\text { feedback session. }\end{array}$ & $26(90 \%)$ & $3(10 \%)$ & $0(0 \%)$ \\
\hline $\begin{array}{l}\text { The 1:1 or small group feedback session with the LI/faculty provided me } \\
\text { with useful feedback to improve my skills. }\end{array}$ & $29(100 \%)$ & $0(0 \%)$ & $0(0 \%)$ \\
\hline The amount of time in the feedback sessions was adequate. & $20(69 \%)$ & $5(17 \%)$ & $4(14 \%)$ \\
\hline $\begin{array}{l}\text { Receiving feedback from my peers on the discussion board helped to } \\
\text { improve my learning. }\end{array}$ & $16(55 \%)$ & $9(31 \%)$ & $4(14 \%)$ \\
\hline $\begin{array}{c}\text { Viewing my peer's video and providing feedback to my peer helped to } \\
\text { improve my learning. }\end{array}$ & $25(86 \%)$ & $3(10 \%)$ & $1(3 \%)$ \\
\hline The final video assessment was an adequate reflection of my performance. & $24(83 \%)$ & $4(14 \%)$ & $1(3 \%)$ \\
\hline $\begin{array}{l}\text { This model allowed me adequate practice and feedback to be successful in } \\
\text { my performance of these psychomotor skills. }\end{array}$ & $21(73 \%)$ & $8(28 \%)$ & $0(0 \%)$ \\
\hline
\end{tabular}

One hundred percent of survey respondents agreed that coaching sessions provided helpful feedback to improve skills. Moreover, $90 \%$ agreed that the pre-class materials helped them to prepare for psychomotor skills, and $72 \%$ agreed that using this coaching model allowed them adequate practice and feedback to be successful in their performance of these psychomotor skills.

Thematic analysis of the open-ended questions was conducted to identify themes related to the coaching model around practice time, effectiveness of coaching, learning and affective skill development, and areas of improvement.

\subsection{Psychomotor Skill Development}

Notably, $73 \%$ of individuals strongly agreed or agreed that there was adequate practice and feedback to be effective in their performance of these skills. Several commented on the additional practice that took place through recording and re-recording videos. By recording a video of themselves performing the task to share with peers or for a grade, students were motivated to attempt several takes, resulting in more practice.

Here, a student talks about the additional practice required to perfect their video: "(I liked best) being able to try and perfect the video for the best optimal grade. It forced me to make multiple attempts which reinforced the knowledge of the skill."

Another benefit of the repetitive video recording was the ability for students to observe and critique their performance. Furthermore, it gave them control of when and how frequently to practice.

\subsection{Affective Skills}

The development of affective skills such as verbal and non-verbal communication skills, building patient report, etc., via the virtual platform presented challenges. Students reported, however, the benefit of seeing a variety of communication and affective styles through viewing peer and instructor videos. Feedback in this area traditionally tends to be from the perspective of the instructor, so to be able to compare, contrast, and learn from watching how several of their peers interact was perceived as highly valuable: "I liked being able to see other student's videos to compare styles of communication and technique. That was the most helpful to me."

\subsection{Instructor Feedback}

Feedback from the 1:1 coaching session with the instructor was reported as most beneficial. Individualized attention from the instructor was a rare opportunity in the virtual classroom (as it is in the traditional onsite classroom) with a large cohort of 72 students. Students valued the time and ability to have their individual questions answered in an environment more conducive to asking questions than in a large group and, consequently, 
came prepared with well-focused questions. "The opportunity to talk 1:1 with instructors and ask specific questions. This gave me the opportunity to reflect on myself and ask more useful questions." Students appreciated the dedicated time with faculty or LIs. "Being able to have 20 min of uninterrupted minutes with a LI was really beneficial."

Additionally, students reported the coaching session created an environment where it was comfortable to make mistakes, which is important for social presence and engagement [4]. "The 1:1 was extremely valuable. It was an easy setting to feel free to make mistakes, and there was plenty of time for feedback."

\subsection{Providing Peer Feedback}

Eighty-six percent of students agreed that viewing a peer's video improved their learning. Articulating constructive feedback forced them to reflect on their own performance. Viewing others' videos also gave them a realistic sense of their progress compared to their peers and provided examples of where and how to improve. Although students were only required to watch one peer video, most reported watching several videos, which may speak to the students' perceived value of watching their peers' performance.

Here, a student comments on the value of their peers' videos and feedback: "[I reviewed] as many videos and read the feedback received in order to improve my own performance on my videos." Another reflects on the value of other perspectives. "It was nice to obtain another perspective on the lab activity, and helpful to watch other students' performance."

\subsection{Receiving Peer Feedback}

Receiving peer feedback was perceived as valuable by $51 \%$ of the respondents. Novice peer feedback captured different perspectives better than the advice from the experienced instructor. Students reported they received feedback about communication and affect from their peers while the instructor focused more on psychomotor skills.

"I thought the discussion boards [peer feedback] were extremely helpful in getting an extra pair of eyes on my performance. This feedback was a great supplement to the 1:1 coaching session, especially since the coaching session generally focused on breaking the skill down into parts, whereas the discussion post required me to practice putting everything together, communication, multiple skills in succession, etc."

There may have been variations in engagement in peer feedback from different students, resulting in fewer students perceiving peer feedback as valuable. Here, one student writes, "The peer feedback did not help me as much as I thought it would. Some of the feedback I received seemed like my video wasn't entirely watched."

\subsection{1:1 versus 2:1 Coaching Session}

One course implemented a 1:1 model while the subsequent course used a 2:1 model and a video of the skill being shown rather than a live participant, with neither emerging as a preference over the other. There were several interesting comments from students regarding the 2:1 model, however. In some cases, they perceived viewing another student's video and hearing feedback in real time was highly beneficial. It either reinforced their own feelings of competency or highlighted new approaches they may not have explored. They reflected that they benefited from hearing about ways to improve the skill that may have not emerged from the 1:1 instruction of their video alone. Learning to provide constructive feedback in person to peers is an important aspect in the learning process that was a nice addition to the 2:1 model and built from the first course providing written peer feedback in a discussion board. "The 2:1 session was AMAZING! I loved how the LI asked both students questions on their video and prompted deeper discussion. So much better than $1: 1 . "$

In other cases, the 2:1 model was viewed as less favorable. Some students noted that there was an uneven allocation of time due to their partner's video being longer. "For 
2:1 sessions, instruct the students on how long their videos should be in order to provide adequate time for the LI to give both students feedback."

\subsection{Unintentional Benefits}

One unintended benefit was the students revealed that they started a "blooper reel" of their various mistakes. Although not instructed to do so, there are many andragogical benefits, such as increasing student camaraderie, developing a social and inclusive presence, creating a safe environment to share (and learn from) mistakes, and supporting discourse and inquiry.

Although the emphasis of benefits of the coaching model is on the learner's experience, there was unsolicited yet consistent positive feedback from both faculty and LIs. The lack of interaction between students and faculty in the online environment and challenges of knowing if students are following class concepts have been challenging and a source of dissatisfaction for faculty. Despite not being in-person, the close interaction with the student in both the 1:1 and the 2:1 coaching model helped to replenish this void and was enthusiastically endorsed.

Here, one faculty member describes her experience in the coaching sessions:

"Wow, I just finished as an LI in 602 doing some 1:1 goniometry coaching and it was SO FUN and super engaging! I was honestly disappointed when I realized I was on my last of six back-to-back students. In addition to really getting a sense of how the students were doing and getting to offer effective in the moment feedback, it was a great opportunity to get to know and interact with them individually."

\subsection{Areas for Improvement}

Students frequently highlighted consistency of the preparatory material for the coaching session as an area for improvement. Inconsistencies across different resources teaching the same skill was often a source of frustration for the novice learners. A selection of students also reported that that an addition of 5-10 more min to the 1:1 and 2:1 coaching sessions would have been better. "A little more time (maybe $10 \mathrm{~min}$ at most to make it 30-min time slots) with 1:1 LI and student sessions would be helpful for me personally." Several students also commented that more time between the coaching session and the time to post the video would have allowed for more practice. From a faculty perspective, the coaching model required additional time to organize, especially the scheduling component. There was also a demand for extra resources, such as the cost of hiring of LIs for coaching sessions, discussion board grading, and final video assessment, although this was offset somewhat by not needing to hire standardized patients, as is typical for the onsite graded psychomotor assessments at the IHP.

\section{Discussion}

March of 2020 brought significant disruption to many industries, including higher education. Many academicians needed to find creative ways to continue to deliver high-quality education using new modalities and learning strategies. With its focus on psychomotor skill development, PT education created specific challenges to learning in an all-virtual environment. As the world is finally reopening and returning to "normal", this is a time for educators worldwide to reflect on educational innovations and decide what to keep, modify, and let go. The innovative coaching model developed and implemented during the COVID-19 pandemic to meet the needs of teaching psychomotor skills in a fully remote environment may have continued utility in onsite and hybrid programs.

This model provided opportunities for practice, feedback, and reflection. Consistent with ELT, this innovative coaching model created opportunities for self-paced practice, application of knowledge in context, and instructor and peer formative and summative feedback and reflection [20]. Introduction of all these essential aspects of learning in the first DPT course set a foundation for continued development of skills necessary for clinical reasoning and lifelong learning. 
Individuals react differently to different types of feedback, and the coaching model was able to deliver feedback in a variety of approaches. Immediate feedback and feedback that provides information to the learner on how to improve rather than just correct the behavior are known to be effective in education [31]. Not only did the coaching session (1:1 and 2:1) provide immediate and purposeful feedback to the student, it created a platform for dialogue whereby the student had the opportunity to engage the instructor in a discussion about the feedback and to help clarify expectations and resolve misunderstandings. Engaging in individual feedback can be difficult for educators in large classrooms, but the dedicated 1:1 time with the instructor created by the virtual coaching model may provide an effective way to accomplish this in the future.

Student-to-student (peer) feedback is known to be important for development [32]. The discussion board component of the coaching model provided opportunities to reflect on action and provide critique to another peer. Survey results indicated that comments from experienced clinicians were more valued over peers. Providing peer feedback offers an excellent opportunity for self-assessment of skills and gives a yardstick for students to measure their own performance [33]. Future implementation of peer feedback should incorporate clear communication of the critical value of peer critique in learning prior to assigning the task.

Students were also advised on their reflective skills. It has been reported that skills necessary for reflection should be taught deliberately, as reflection has not been shown to occur spontaneously [34]. Both Sadler and Boud [35] discuss the importance of reflecting to close the gap between current and desired performance and claim it is often the missing element $[35,36]$. The final video assignment helped students recognize performance gaps and develop strategies for improvements.

Despite its value, research has demonstrated an overemphasis on knowledge and skill acquisition in curricula at the expense of improving skills in reflective practice $[37,38]$. The coaching model included a reflective component that was reviewed and graded and was aimed at addressing the importance of structure to guide reflection. Especially early in the learning process, learners benefit from feedback on the content and process of their reflection [15]. Students' direct involvement by assessing their work and frequent opportunities to reflect on goals, strategies, and outcomes are highly effective in enhancing learning and achievement [35,36]. While large class demonstrations during onsite practice of psychomotor skills may provide an opportunity for reflective learning, the virtual coaching model offers more opportunities and is self-paced for the individual learner.

Students were performing these skills in their homes, so there were limitations related to camera angles and the environment. The environment was rarely optimal (there are no high-low mats in homes of DPT students). This created opportunities for problemsolving in the application of skill acquisition due to these environmental challenges. The psychomotor practice of the skills took on a much more cognitive process than if in person. Students needed to break tasks down into distinct steps. The student had to think about and explain these steps to the instructor and participant, creating opportunities for kinesthetic, visual, and explicit learning.

\section{Limitations}

One limitation of the study was the lower survey response rate making it difficult to generalize results. Students had already ended their semester, so this may have affected responses. Since this study was performed as a quality improvement initiative, the survey was only distributed twice. In the future, providing dedicated class time to complete the survey may result in a higher response rate.

The coaching model was time- and resource-intensive, resulting in the need to hire LIs and adjunct faculty for the coaching sessions and grading discussion board posts and final video assignments. Moreover, faculty were learning new academic technologies and theoretical approaches to teaching virtually. Increased time for preparation and need for faculty development in online andragogy are important for faculty support. Ultimately, 
in a blended or hybrid program, the coaching model may result in less in-person lab time overall, but that would need to be investigated in future studies.

The coaching model can be improved in several ways in future. Areas for future modification include allowing 5-10 additional $\mathrm{min}$ for the coaching sessions and providing videos for pre-work that demonstrated techniques in one consistent way to avoid confusion during self-practice. To reduce the burden of having a friend of family member be available multiple times for coaching sessions, allowing students to bring pre-recorded videos to the coaching session would help in easier scheduling. The videos could also be paused or replayed as needed to allow for a closer evaluation of skills and feedback. Additionally, providing students with tips for optimal viewing and camera angles learned by faculty via telehealth during the pandemic may enhance the experience. Finally, further research is warranted in assessing the advantages of the 1:1 coaching session vs. the 2:1 coaching experience, and the timing of 1:1 vs. 2:1 coaching session.

\section{Conclusions}

The pandemic has resulted in global disruption of the higher education system and challenges for health professions education, but it also provided the opportunity for innovation and reflection on traditional teaching methods. Although the new coaching model described in this paper evolved from the need for a quick transition to a fully remote curriculum due to social distancing restrictions, it serendipitously resulted in having a broader relevance. As programs continue to navigate uncertain and evolving educational and clinical changes, it has potential for application in future blended and hybrid models [36]. This coaching model could be easily adapted to hybrid and traditional onsite health professions curricula and may have andragogical benefits by increasing faculty feedback and peer feedback opportunities, allowing for greater practice and reflection necessary for the development of clinical reasoning.

Author Contributions: Conceptualization, L.P., L.S., E.C. and S.G.; methodology, L.P. and S.G.; writing — original draft preparation, L.P., L.S., E.C. and S.G.; writing—review and editing, L.P., L.S., E.C. and S.G. All authors have read and agreed to the published version of the manuscript.

Funding: This research received no external funding.

Institutional Review Board Statement: The project was undertaken as a Quality Improvement Initiative at MGH IHP and as such was not formerly supervised by the Internal Review Board per their policies.

Informed Consent Statement: Not applicable.

Data Availability Statement: Not applicable.

Acknowledgments: We would like to thank the students and lab instructors who engaged in this learning activity.

Conflicts of Interest: The authors declare no conflict of interest.

\section{Appendix A}

Coaching Model Survey

In 601,602 , and 603 , faculty used a coaching model to address learning of psychomotor skills (vitals, mobility, ROM, MMT, etc.) in the virtual environment. You were provided with pre-class materials (handouts, videos) to review, then attended a 1:1 or small group with faculty or lab instructor session to get feedback. This was followed by peer feedback in some cases through the discussion board and then a video final assessment that was graded. We would like your feedback specifically on this learning activity/model. This will help us to improve the activity going forward. The survey is anonymous. 
Please rate these statements from strongly disagree to strongly agree:

1. The pre-class materials helped to prepare for the 1:1 or small group feedback session.

2. The 1:1 or small group feedback session with the LI/faculty provided me with useful feedback to improve my skills.

3. The amount of time in the feedback sessions was adequate.

4. If not, how much time would you recommend?

5. Receiving feedback from my peers on the discussion board helped to improve my learning.

6. Viewing my peer's video and providing feedback to my peer helped to improve my learning.

7. Grossly, how many videos of your peers did you watch? Fill in number.

8. The final assessment was an adequate reflection of my performance.

9. This model allowed me adequate practice and feedback to be successful in my performance of these psychomotor skills.

Open response:

What did you like best about the learning experiences/model?

What would you change about the learning experiences/model?

\section{References}

1. Brandon, A.F.; All, A.C. Constructivism theory analysis and application to curricula. Nurs. Educ. Perspect. 2010, 31, 89-92. [PubMed]

2. Brooks, M.G.; Brooks, J.G. The courage to be constructivist. Educ. Leadersh. 1999, 57, 18.

3. Thomas, A.; Menon, A.; Boruff, J.; Rodriguez, A.M.; Ahmed, S. Applications of social constructivist learning theories in knowledge translation for healthcare professionals: A scoping review. Implement. Sci. IS 2014, 9, 54. [CrossRef] [PubMed]

4. Ubbes, V.A.; Black, J.M.; Ausherman, J.A. Teaching for understanding in health education: The role of critical and creative thinking skills within constructivism theory. J. Health Educ. 1999, 30, 67.

5. Jette, D.U.; Macauley, K.; Levangie, P.K. A theoretical framework and process for implementing a spiral integrated curriculum in a physical therapist education program. J. Phys. Ther. Educ. 2020, 34, 206-214. [CrossRef]

6. Tam, M. Constructivism, instructional design, and technology: Implications for transforming distance learning. Educ. Technol. Soc. 2000, 3, 50-60.

7. Kilner, J.M.; Lemon, R.N. What we know currently about mirror neurons. Curr. Biol. 2013, 23, R1057-R1062. [CrossRef]

8. Seymour-Walsh, A.E.; Weber, A.; Bell, A.; Smith, T. Teaching psychomotor skills online: Exploring the implications of novel coronavirus on health professions education. Rural Remote Health 2020, 20, 6132. [CrossRef]

9. Dornan, T.; Scherpbier, A.; Boshuizen, H. Supporting medical students workplace learning: Experience-Based learning (ExBL). Clin. Teach. 2009, 6, 167-171. [CrossRef]

10. Kolb, A.Y. The Kolb Learning Style Inventory 4.0: A Comprehensive Guide to the Theory, Psychometrics, Research on Validity and Educational Applications; Hay Group: Philadelphia, PA, USA, 2013.

11. Kolb, A.Y.; Kolb, D.A.; Passarelli, A.; Sharma, G. On becoming an experiential educator: The educator role profile. Simul. Gaming 2014, 45, 204-234. [CrossRef]

12. Baker, M.; Cline, L. The coach phenomena: Examining the validity of the kolb educator role profile in preservice agricultural education. J. Agric. Educ. 2019, 60. [CrossRef]

13. Armson, H.; Lockyer, J.M.; Zetkulic, M.; Könings, K.D.; Sargeant, J. Identifying coaching skills to improve feedback use in postgraduate medical education. Med. Educ. 2019, 53, 477-493. [CrossRef]

14. Watling, C.; LaDonna, K.A.; Lingard, L.; Voyer, S.; Hatala, R. 'Sometimes the work just needs to be done': Socio-Cultural influences on direct observation in medical training. Med. Educ. 2016, 50, 1054-1064. [CrossRef]

15. Deiorio, N.M.; Carney, P.A.; Kahl, L.E.; Bonura, E.M.; Juve, A.M. Coaching: A new model for academic and career achievement. Med. Educ. Online 2016, 21, 33480-33484. [CrossRef]

16. Sadler, D.R. Formative assessment: Revisiting the territory. Assess. Educ. Princ. Policy Pract. 1998, 5, 77-84. [CrossRef]

17. Jensen, G.M.; Gwyer, J.; Shepard, K.F. Expert practice in physical therapy. Phys. Ther. 2000, 80, 28-43. [CrossRef] [PubMed]

18. Ziebart, C.; MacDermid, J.C. Reflective practice in physical therapy: A scoping review. Phys. Ther. 2019, 99, 1056-1068. [CrossRef]

19. Moore, C.; Teather, S. Engaging students in peer review: Feedback as learning. Issues Educ. Res. 2013, $23,196$.

20. Wainwright, S.F.; Shepard, K.F.; Harman, L.B.; Stephens, J. Novice and experienced physical therapist clinicians: A comparison of how reflection is used to inform the clinical decision-making process. Phys. Ther. 2010, 90, 75-88. [CrossRef] [PubMed]

21. Schön, D.A. Educating the Reflective Practitioner: Toward a New Design for Teaching and Learning in the Professions, 1st ed.; Jossey-Bass: San Francisco, CA, USA, 1987.

22. Caeiro, C.; Cruz, E.B.; Pereira, C.M. Arts, literature and reflective writing as educational strategies to promote narrative reasoning capabilities among physiotherapy students. Physiother. Theory Pract. 2014, 30, 572-580. [CrossRef] 
23. Cross, V. Introducing physiotherapy students to the idea of 'reflective practice'. Med. Teach. 1993, 15, 293-307. [CrossRef] [PubMed]

24. Roter, D.L.; Larson, S.; Shinitzky, H.; Chernoff, R.; Serwint, J.R.; Adamo, G.; Wissow, L. Use of an innovative video feedback technique to enhance communication skills training. Med. Educ. 2004, 38, 145-157. [CrossRef]

25. Lahteenmaki, M.-L. Reflectivity in supervised practice: Conventional and transformative approaches to physiotherapy. Learn. Health Soc. Care 2005, 4, 18-28. [CrossRef]

26. World Health Organization. International Classification of Functioning, Disability and Health: ICF; World Health Organization: Geneva, Switzerland, 2001.

27. Pinnow, T. Teaching Movement Disciplines in a Time of Disruption; 2020.

28. PhysioU. PhysioU: Top-Rated Rehab Guide for Student \& Professional. Available online: https://www.physiou.health/ (accessed on 20 June 2021).

29. Berrett, D. The unwritten rules of college.(transparency in teaching and learning in higher education). Chron. High. Educ. 2015, 62, A26-A29.

30. Winkelmes, M.; Boye, A.; Tapp, S.; Felten, P.; Finley, A. Transparent Design in Higher Education Teaching and Learning: A Guide to Implementing the Transparency Framework Institution-Wide to Improve Learning and Retention, 1st ed.; Stylus Publishing: Sterling, VA, USA, 2019.

31. Shute, V.J. Focus on formative many videos and reafeedback. Rev. Educ. Res. 2008, 78, 153-189. [CrossRef]

32. Wisniewski, B.; Zierer, K.; Hattie, J. The power of feedback revisited: A meta-analysis of educational feedback research. Front. Psychol. 2019, 10, 3087. [CrossRef]

33. Nicol, D.J.; Boyle, J.T. Peer instruction versus class-wide discussion in large classes: A comparison of two interaction methods in the wired classroom. Stud. High. Educ. 2003, 28, 457-473. [CrossRef]

34. Wald, H.S.; Davis, S.W.; Reis, S.P.; Monroe, A.D.; Borkan, J.M. Reflecting on reflections: Enhancement of medical education curriculum with structured field notes and guided feedback. Acad. Med. 2009, 84, 830-837. [CrossRef]

35. Boud, D. Sustainable assessment: Rethinking assessment for the learning society. Stud. Contin. Educ. 2000, 22, 151-167. [CrossRef]

36. McDonald, B.; Boud, D. The Impact of self-assessment on achievement: The effects of self-assessment training on performance in external examinations. Assess. Educ. Princ. Policy Pract. 2003, 10, 209-220. [CrossRef]

37. Jensen, G.M.; Shepard, K.F.; Hack, L.M. The novice versus the experienced clinician: Insights into the work of the physical therapist. Phys. Ther. 1990, 70, 314-323. [CrossRef] [PubMed]

38. Gagnon, K.; Young, B.; Bachman, T.; Longbottom, T.; Severin, R.; Walker, M.J. Doctor of physical therapy education in a hybrid learning environment: Reimagining the possibilities and navigating a "new normal". Phys. Ther. 2020, 100, 1268-1277. [CrossRef] [PubMed] 